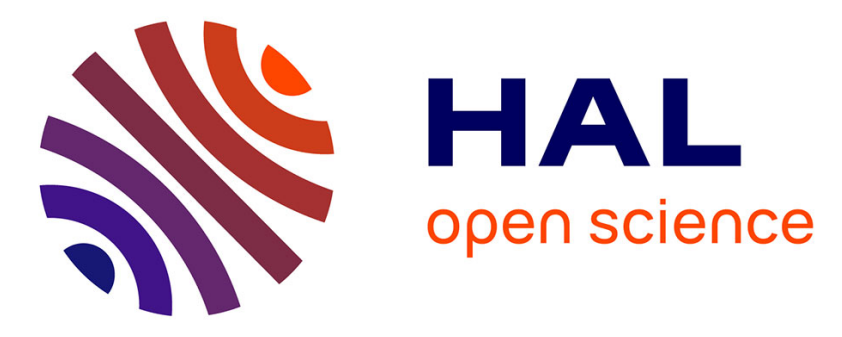

\title{
Triathlon and Ultra-Endurance Events in Tropical Environments
}

\author{
Clovis Chabert, Eric Hermand, Olivier Hue
}

\section{To cite this version:}

Clovis Chabert, Eric Hermand, Olivier Hue. Triathlon and Ultra-Endurance Events in Tropical Environments. Heat Stress in Sport and Exercise, Springer International Publishing, pp.283-296, 2019, 10.1007/978-3-319-93515-7_15 . hal-03187448

\section{HAL Id: hal-03187448 \\ https://hal.science/hal-03187448}

Submitted on 1 Apr 2021

HAL is a multi-disciplinary open access archive for the deposit and dissemination of scientific research documents, whether they are published or not. The documents may come from teaching and research institutions in France or abroad, or from public or private research centers.
L'archive ouverte pluridisciplinaire HAL, est destinée au dépôt et à la diffusion de documents scientifiques de niveau recherche, publiés ou non, émanant des établissements d'enseignement et de recherche français ou étrangers, des laboratoires publics ou privés. 
3 Chabert $\mathrm{C}^{\dagger}$, Hermand $\mathrm{E}^{\dagger}$, Hue O.

5 Laboratory « Adaptations au Climat Tropical, Exercice et Santé » (ACTES; EA 3596), French West

6 Indies University, Pointe-à- Pitre, Guadeloupe, France.

$7 \quad$ : Both authors contributed equally to this work.

\section{Abstract}

Physical performance in tropical environments, which combine heat and high humidity, is a 11 challenge that requires specific preparation. The high humidity of a tropical climate alters

12 thermoregulatory capacity by limiting the rate of sweat evaporation. Proper management of whole-

13 body temperature is thus essential to complete an endurance event like a long-distance triathlon or 14 an ultramarathon in such an environment. In triathlon and ultra-endurance races, which can last 15 from 8 to $20 \mathrm{~h}$, performance in tropical settings is closely linked to the capacity to maintain

16 hydration status. Indeed, the rate of withdrawal in these longer events has been associated with

17 water intake, with many finishers showing alterations in electrolyte (e.g. sodium) balance. To

18 counterbalance the impact of a tropical climate and maintain performance, several countermeasures

19 can be adopted, such as using hydration and cooling strategies, and heat acclimation.

\section{Influence of heat on performance and health}

\section{$21 \quad 1.1$ Specificity of the triathlon}

The Ironman and Challenge triathlon series are trademark brands for long-distance triathlons 
24 professional triathletes complete the distance in under $7 \mathrm{~h}$ and $50 \mathrm{~min}$, whereas age group athletes vary from 9 to $13 \mathrm{~h}$ and more, making this one of the longest endurance races. The duration depends on several factors, including terrain (i.e. course route and geography) and environmental conditions.

27 For example, hot and humid climates impact on performance and the rate of withdrawal, as observed in the Kona (Hawaii) Ironman World Championships every October (Giambelluca et al. 2014; Stiefel et al. 2013): top age-groupers were slower at Hawaii than at their qualifier races (Stiefel et al. 2013), and abandon rate can reach 10\%, a high proportion considering the fitness level of athletes participating in this particular event, more resistant to heat stress (Cheung and McLellan 1998; Ironman 2018b). Similarly, more than $25 \%$ of the athletes did not reach the finish line at the inaugural Ironman Vichy in 2015 , which was held in unusually hot conditions $\left(31 \sim 35^{\circ} \mathrm{C}\right)$, in contrast to North American races with a minimum 95\% finish rate (Britt 2011).

The following sections detail how thermal stress can specifically impact each of the triathlon legs: swimming, cycling and running.

\subsubsection{Swimming}

Most long distance triathlons allow neoprene wetsuits to be worn for the swim leg as long as water temperature does not exceed $24.5^{\circ} \mathrm{C}$. Between $24.5^{\circ} \mathrm{C}$ and $28.8^{\circ} \mathrm{C}$, athletes who choose to wear a wetsuit are allowed to participate, but are not eligible for age-group awards or for qualifying slots for the Ironman World Championships, and over $28.8^{\circ} \mathrm{C}$ wetsuits are prohibited (Ironman 2018). With its enhanced buoyancy, the neoprene wetsuit reduces ventilation and $\mathrm{O}_{2}$ consumption $\left(\mathrm{V}_{2}\right)$ at a given swimming speed, and therefore metabolic heat production (Trappe et al. 1996). However, wetsuits reduce heat dissipation capacity and can lead to high core body temperatures and dehydration (Kerr et al. 1998; Laursen et al. 2006). Hence, although banning wetsuits in warm water might impair swimming performance, it might also decrease the risk of hyperthermia.

Interestingly, Kerr et al. (Kerr et al. 1998) showed in a simulated Olympic triathlon that core temperature did not change by wearing a wetsuit, thought to limit thermoregulatory mechanisms 
49 through heat-insulating properties of neoprene, as excess heat was still transferred at the periphery,

50 leading to a higher skin temperature. A subsequent field study confirmed that core temperature 51 remained around $38^{\circ} \mathrm{C}$ in well-trained athletes wearing a wetsuit in $20.5^{\circ} \mathrm{C}$ water during a $3.8 \mathrm{~km}$ 52 swim (Laursen et al. 2006). This was again confirmed by a case report in which an athlete's core 53 temperature was continuously monitored during an Ironman (Laursen et al. 2009). In $29.5^{\circ} \mathrm{C}$ water, 54 another study showed that the core temperature of moderately trained athletes increased by an 55 average $0.7^{\circ} \mathrm{C}$ and remained under $38^{\circ} \mathrm{C}$ during a non-wetsuit half-Ironman (Figure 1; (Baillot and 56 Hue 2015)). Thus, no study appears to have shown a dangerous elevation in core temperature during 57 the swim leg of long-distance triathlon events. Moreover, while 13 of the 14 deaths in triathlon 58 races from 2006 to 2008 occurred during the swim leg, pre-existing cardiovascular abnormalities 59 seem to have been the major factor, ruling out hyperthermia as a potential cause (Harris et al. 2010).

\subsubsection{Cycling}

When cycling, some of the heat produced by the muscles is dissipated via convection. This

62 however, depends on a sufficient temperature gradient between the skin and ambient air.

63 Convection is therefore limited in hot conditions when air temperatures exceeds $35^{\circ} \mathrm{C}$. Heat is also

64 dissipated during cycling via the evaporation of sweat, which depends on the water vapor partial 65 pressure gradient between air and skin. Like convection, this mechanism is reduced in humid 66 environments, making performance in a tropical environment challenging as thermoregulatory 67 efficiency is reduced (Nybo 2010). In a tropical climate $\left(31-33^{\circ} \mathrm{C}, 70-75 \% \mathrm{RH}\right.$ ), one-hour of 68 pedalling at a submaximal intensity increases core temperature, heart rate, sweat rate and water loss 69 (Saat et al. 2005a; Saat et al. 2005b; Voltaire et al. 2003). These results can be extrapolated to 70 describe the physiological impact of 4-6-h events, especially if the cycling course includes hills, 71 where the diminished air speed reduces heat dissipation (Nybo 2010). Laboratory-controlled studies 72 showed that increasing ambient temperature impaired cycling capacity when relative humidity was 
74 cycling race held in Guadeloupe $\left(31.1^{\circ} \mathrm{C}, 75.6 \% \mathrm{RH}\right)$, tympanic temperatures measured

75 immediately after the stages never exceeded $2^{\circ} \mathrm{C}$ of resting pre-race values (Hue et al. 2006). In

76 contrast to the variability associated with stage racing in a peloton, triathletes will adopt a much

77 steadier pace during racing in some cases to "save their legs" for the following marathon (Wu et al.

78 2015). Interestingly, Baillot et al. (Baillot and Hue 2015) showed a negative correlation between

79 body mass and the evolution of core temperature throughout the cycling leg, implying greater heat

80 storage and inertia. A bigger body thus presents a larger surface to preserve heat exchange at high

81 velocity, even in a hot and humid environment (Nielsen 1996).

In summary, the high velocities and individual nature of cycling in the triathlon support heat dissipation by convection on the condition that air temperature is lower than skin temperature. In a thermally challenging environment, sweat evaporation is the main avenue for heat dissipation but it is limited by the high humidity of a tropical environment. Nevertheless, triathletes appear to show adequate thermoregulatory capability to prevent excessive hyperthermia, mainly through intensity management and pacing strategies (Baillot and Hue 2015).

\subsubsection{Running}

Of the three sports in the triathlon, running may carry the greatest risk of hyperthermia for

90 triathletes competing in a tropical climate. Several factors come into play. Firstly, although running

91 is faster than swimming, air possesses neither the heat capacity nor transfer celerity of water, hence

92 limiting the quantity of heat energy transferred from the body. Secondly, unlike in cycling, the

93 lower speed associated with running does not allow for excess heat dissipation via convection

94 (Nielsen 1996). These factors can have a strong negative impact on running performance (Kenefick

95 et al. 2007), particularly the marathon (Ely et al. 2007). This negative impact is amplified (i) by a

96 heavier body mass, which, at a given pace, requires more energy for running propulsion and

97 therefore produces more heat, and (ii) in heavier athletes running in a hot/humid environment 
98 limiting heat exchange by convection and evaporation, who display greater imbalance between heat

99 production and dissipation, even at slower paces (Marino et al. 2000).

While the core temperature data of professional triathletes in the Hawaii Ironman or other 101 tropical locations are currently not available, a few studies of moderately to very well trained age 102 group athletes have shown that none of them suffered from heat-related illness and excessive 103 increases in core temperature (Laursen et al. 2006) (Figure 1; (Baillot and Hue 2015; Del Coso et al. 104 2014)). In the report from Laursen et al. (Laursen et al. 2006) 7 out of 10 well trained triathletes 105 performed a high-level sub-10-hour performance at Ironman Western Australia in temperate but 106 humid conditions $\left(23.3^{\circ} \mathrm{C}, 60 \% \mathrm{RH}\right)$, and the average core body temperature remained close to $10738^{\circ} \mathrm{C}$. Despite a much hotter and more humid environment in Guadeloupe $\left(27.2^{\circ} \mathrm{C}, 80 \% \mathrm{RH}\right)$, the 108 average body temperature of moderately trained athletes during a half-Ironman run was $38.2^{\circ} \mathrm{C}$ and 109 none of them reached $40^{\circ} \mathrm{C}$ (Baillot and Hue 2015). These values are not surprising given the 110 relative intensity and absolute workload at which most long-distance triathlon races are performed, 111 which is in contrast to shorter events performed at a higher intensity and thus higher heat production 112 (Siegel et al. 2010; Baillot and Hue 2015). The importance of exercise intensity was confirmed in 113 dryer conditions in a study showing that the fastest athletes exhibited the highest core temperatures 114 (Del Coso et al. 2014).

\subsection{Specificity of ultra-endurance events}

\subsubsection{Ultra-endurance in the heat}

Ultramarathons last more than $6 \mathrm{~h}$ (Zaryski and Smith 2005). In the past decade, trail running 119 races have become a major ultra-endurance sport. Since the first edition of the Ultra Trail du Mont 120 Blanc (160 km and $+10,000 \mathrm{~m}$ of elevation), the number of finishers has grown from 67 in 2003 to 1685 in 2017. This kind of effort involves several physiological and psychological parameters that 
road terrains, elevation profiles (positive: D+ and negative: D- changes), and distances, all of which

124 greatly complicate the attempt to understand how environmental conditions affect performance.

125 Marathon races have more standardized characteristics, facilitating the comparison of performances

126 in order to study the role played by heat (see chapter 12). Based on the analysis of winners' times in

127 several marathons, (Maughan 2010) et al., 2010 determined that the best running temperature is

128 between $10^{\circ} \mathrm{C}$ to $12^{\circ} \mathrm{C}$ for elite athletes. Beyond this temperature, the analysis of 136 marathons

129 performed between a wet-bulb globe temperature (WBGT) of 5 and $25^{\circ} \mathrm{C}$ showed a decrease in

130 performance with an increase in WBGT (Figure 2; (Ely et al. 2007)). Interestingly, these authors

131 also showed that slower runners, who are exposed to heat for a longer time than faster runners, are

132 more affected by temperature. For ultramarathon distances, the same effect of hot environments on

133 performance was observed in a study that examined running times in the Western States Endurance

134 Run (161 km and $6000 \mathrm{~m} \mathrm{D+)} \mathrm{in} 2006$ and 2007 (Parise and Hoffman 2011). In these two editions

135 (Figure 3), the authors followed 50 runners who had finished the race in both years to investigate

136 the effect of temperature changes from $7-38^{\circ} \mathrm{C}$ in 2006 to $2-30^{\circ} \mathrm{C}$ in 2007 . Independently of their

137 level, the athletes were $8 \%$ slower in the hot condition (2006) than in the cooler environment

138 (2007), and the withdrawal rate was $14 \%$ higher in 2006. In this study, slower runners did not

139 appear to be more impacted by the hot environment, but this observation was probably due to the

140 longer time running at a comfortable temperature (i.e. night).

\subsubsection{Hydration requirements during ultra-endurance exercise in the heat}

During muscle contraction, only $\sim 25 \%$ of the substrate energy is converted to mechanical

143 work, with the other $\sim 75 \%$ released as heat. Effective thermoregulation during exercise depends on

144 the balance between the absolute mechanical work generated by the athlete and the heat loss process

145 (Chapter 2). Ultramarathons, characterized by the maintenance of a low relative exercise intensity over very long periods, do not significantly challenge the heat balance in temperate environments.

147 However, maintaining mechanical load over a longer time may challenge heat balance in athletes, 
148 especially when competing in hot and/or humid environments. Furthermore, environmental heat 149 stress (i.e. temperature) reduces dry heat loss, due to the small (or even negative) temperature 150 gradient between the skin and air, which progressively places sweat evaporation as the only 151 mechanism available for the organism to dissipate endogenous heat (Brotherhood 2008; Taylor 152 2006). Indeed, at in $30^{\circ} \mathrm{C}$ conditions a dry heat loss of $75 \mathrm{~W}$ is observed whereas at $40^{\circ} \mathrm{C}$, it induces 153 a dry heat gain of $75 \mathrm{~W}$, increasing the sweating rate require to maintain body core temperature 154 (Gagnon et al. 2013). Thus, ultramarathons performed in a hot environment require bigger volumes 155 of water intake to compensate for increased water losses. During the Badwater Ultramarathon of $1562012(217 \mathrm{~km}$ and $4000 \mathrm{~m} \mathrm{D}+)$, the temperature oscillated from $10.1^{\circ} \mathrm{C}$ at night to $46.6^{\circ} \mathrm{C}$ during 157 the day. The follow-up of 4 runners who completed the race in $36 \pm 3 \mathrm{~h}$ showed a mean water intake 158 of $34 \pm 13 \mathrm{~L}$ (Brown and Connolly 2015). On average, each athlete drank $0.93 \mathrm{~L} . \mathrm{h}^{-1}$, whereas on 159 completion of the Biel Ultramarathon in Switzerland (100 km and $645 \mathrm{~m} \mathrm{D+})$, in a temperate 160 environment varying from 8 to $28^{\circ} \mathrm{C}$, the runners consumed $0.65 \mathrm{~L} \cdot \mathrm{h}^{-1}$ (Knechtle et al. 2011). When 161 the distances of these two races were linked to elevation changes (100 m D+ corresponds to $1 \mathrm{~km}$ of 162 distance), the corrected distance for the Biel Ultramarathon was $106.45 \mathrm{~km}$ and $257 \mathrm{~km}$ for 163 Badwater. According to these corrected distances, the Badwater runners drank almost twice as 164 much water as the Biel runners $\left(0.13 \mathrm{~L} \cdot \mathrm{km}^{-1}\right.$ and $0.069 \mathrm{~L} \cdot \mathrm{km}^{-1}$, respectively), despite the higher 165 mechanical workload developed during the Biel Ultramarathon due to its shorter distance and lower 166 elevation change (6.6 min. $\mathrm{km}^{-1}$ vs. 8.5 min. $\mathrm{km}^{-1}$ for Badwater). The characteristics of the 2007 167 Peninsula Ultra Fun Run (PUFfeR) of South Africa (80 km and $1000 \mathrm{~m} \mathrm{D+)}$ were close to those of 168 the Biel Ultramarathon, but the participants were subjected to lower environmental temperatures $169\left(8-20^{\circ} \mathrm{C}\right)$. The runners drank less during this more temperate race than during the Biel 170 Ultramarathon (0.028 L.km ${ }^{-1}$ and 0.069 L.km ${ }^{-1}$, respectively) (Tam et al. 2009). Analysis of the 171 hydration status of 16 ultramarathon runners $(161 \mathrm{~km}, 7000 \mathrm{~m} \mathrm{D+})$ in a hot environment $172\left(4.8-37.8^{\circ} \mathrm{C}\right)$ showed that finishers $(\mathrm{n}=6)$ had drunk significantly more water at the $48^{\text {th }}$ kilometer 173 than non-finishers $(\mathrm{n}=10)$ (Stuempfle et al. 2011). However, the authors were unable to determine 
174 whether beverage intake was directly linked to finishing capacity or if it was due to other factors, 175 such as the experience or endurance capacity of the runners. A second study performed during a $176160-\mathrm{km}$ foot race (positive elevation not known) in temperatures that peaked at $38^{\circ} \mathrm{C}$ followed only 177 those runners who had completed at least one previous ultramarathon among the top 50\% (Glace et 178 al. 2002). The authors showed that, despite the homogenous level and experience of these runners, 179 non-finishers also drank significantly less than finishers $(-35 \%, \mathrm{p}<0.01)$. All these data confirmed 180 the relationship between event temperature and water intake that is crucial to health and 181 performance. A study during the Gwada Run of 2011, a 6-day multi-stage race for a total of $142 \mathrm{~km}$ 182 under tropical conditions $\left(30 \pm 2.4^{\circ} \mathrm{C}\right.$ and $82 \pm 4 \% \mathrm{RH}$ ) showed a sweat loss of $0.19{\mathrm{~L} . \mathrm{km}^{-1}}^{-}$(Hue et al. 183 2014). Yet water intake $(1.5 \pm 0.3 \mathrm{~L}$ per stage) was probably distorted by the shortness of the stages 184 (from 16 to $21 \mathrm{~km}$ ), which enabled athletes to tolerate transient dehydration during the races ($185 \quad 4.2 \pm 0.9$ L per stage).

\section{Countermeasures to optimize performance and health}

\subsection{Hydration}

Limiting dehydration during triathlons and ultramarathons in hot environments seems to be

190 essential to maintain the exercise workload over many hours. The role of hydration in a tropical

191 climate (see chapter 6) is critical since it has been shown that hyperthermia and dehydration are 192 worse than hyperthermia alone (Sawka et al. 2001; Sawka and Noakes 2007). Despite contradictory 193 observations on influencing thermoregulation and core temperature (Latzka et al. 1997; Ross et al. 194 2012), it seems that hyperhydration can delay the development of dehydration (Latzka and Sawka 195 2000; Latzka et al. 1997; Sawka et al. 1984). However, hyperhydration does not seem to lead to 196 better performances during a laboratory-based $46 \mathrm{~km}$ cycling time trial by elite cyclists (Ross et al. 197 2012) or a 60 min run in endurance trained runners (Scheadler 2009). As hyperhydration results in 
non-negligible added body weight, it may not be an advantage for running performance, which is 199 greatly affected by extra weight (Teunissen et al. 2007). In addition, it does not enhance 200 thermoregulation in a hot and humid climate and augments the risk of hyponatremia (Noakes et al. $2012005)$.

In the triathlon, although hydration depends very much on the availability of adequate means

204 from dehydration symptoms in hot and humid events, despite occasional significant water loses 205 (Baillot and Hue 2015; Del Coso et al. 2014; Laursen et al. 2006; Speedy et al. 2001). This suggests 206 that the hydration strategies employed by the athletes meet the body's water requirements (Kenefick 207 2018).

Maintaining optimal hydration is more complicated than it would seem in the ultramarathon.

209 Indeed, analysis of the hydration status of ultramarathon runners in 2 different races showed that 210 finishers had drunk significantly more water than non-finishers, even if the runners' experience was 211 taking into account (Glace et al. 2002; Stuempfle et al. 2011). In contrast, slower runners became 212 over-hydrated because they feared dehydration, which may lead to hyponatremia (Hew-Butler et al. 213 2008; Noakes 2007). Hyponatremia however, is not only due to over-hydration, but may be the 214 consequence of insufficient sodium intake during the race (Glace et al. 2002; Stuempfle et al. 2011). 215 In a hot environment, hyponatremia affected 30-50\% of ultramarathon finishers, reflecting the 216 inadequate or incorrect hydration strategies of many runners (Glace et al. 2002; Hoffman et al. 217 2012; Lebus et al. 2010). Thus, better sodium intake during ultramarathons could contribute to 218 better performances by stimulating thirst, increasing voluntary fluid intake, enhancing intestinal 219 glucose and water absorption, optimizing extracellular and intracellular fluid balance, and 220 potentially mitigating the occurrence of clinically significant episodes of hyponatremia (Maughan 221 1991; Shirreffs and Sawka 2011; Speedy et al. 1999; Vrijens and Rehrer 1999). 


\subsection{Hydration policy and implementation}

In a triathlon field study, oral salt supplementation improved half-Ironman performance 225 through faster cycling $(\mathrm{p}<0.05)$ and showed a similar trend in the running leg $(\mathrm{p}=0.06)$, with 226 reduced sweat rate and limited electrolyte deficit (Del Coso et al. 2016). The consensus 227 recommendation is thus to ingest 0.5 to $0.7 \mathrm{~g} \cdot \mathrm{L}^{-1} \cdot \mathrm{h}^{-1}$ for long endurance races (Von Duvillard et al. 228 2004) and up to 1.5 g. $\mathrm{L}^{-1} \cdot \mathrm{h}^{-1}$ for athletes prone to develop muscle cramping (Bergeron 2003). 229 However, adding salt to the consumed water is not sufficient to avoid hyponatremia if athletes over230 drink during a race $(73 \%$ of severe symptomatic hyponatremia found after an Ironman (Speedy et 231 al. 1999)).

(Hoffman and Stuempfle 2014) observed no advantage to sodium-enriched beverages during a $161-\mathrm{km}$ ultramarathon performed by all levels of athletes in heat $\left(38^{\circ} \mathrm{C}\right)$. This result may have been 234 due to a variation in sodium intake from solid food and/or to the tolerance of faster runners to 235 hypohydration and hyperthermia (Baillot et al. 2014; Hue et al. 2014).

\subsection{Cooling}

Cooling strategies such as cold drink ingestion or cold-water immersion to reduce the thermal

239 load may enhance performance in the heat (see chapter 7). This effect has been manifested in 240 cyclists (Figure 4; (Burdon et al. 2013; Riera et al. 2016; Tran Trong et al. 2015) and runners as a 241 longer time to exhaustion (Siegel et al. 2010; Siegel et al. 2012; Yeo et al. 2012). Wearing cooling 242 garments prior to or during exercise has proven to be performance-effective in hot and humid 243 climates (Arngrimsson et al. 2004; Hasegawa et al. 2005; Luomala et al. 2012), but they are 244 difficult, impractical and potentially not allowed to be used during official long-distance events.

Other studies have focused on cooling strategies, but the exercise duration has been relatively 
247 extrapolated for long to ultra-long events. Spraying or pouring water over the face and/or body can 248 improve performance in tropical conditions. For example, pouring cold water over the skin will 249 reduce skin temperature before dripping off the body, and transiently improve thermal comfort. 250 Cooling the head in this manner resulted in a 51\% increase in cycling time to exhaustion at $75 \%$ $251 \mathrm{VO}_{2 \max }$ (Ansley et al. 2008), with similar effects recently observed in running (Stevens et al. 252 2017b). Neck cooling during a 90-min running trial in a hot environment $\left(30.4^{\circ} \mathrm{C}\right.$ and $\left.53 \% \mathrm{RH}\right)$ 253 increased the distance covered by $7.4 \%$ with no change in rectal temperature (Tyler and Sunderland 254 2011). A similar effect was found with menthol ingestion, as it activates cold dermal sensors 255 (Stevens and Best 2017). Mixed into a cold beverage, menthol did not lower core body temperature 256 but had a positive effect on thermal sensation and running/cycling performances over various 257 distances in tropical climate (Stevens et al. 2016; Tran Trong et al. 2015). Indeed, Stevens et al. 2582016 showed that a menthol mouth rinse every kilometre $(25 \mathrm{~mL}$ at a concentration of $0.01 \%)$ 259 during a running time trial in the heat significantly improved $5-\mathrm{km}$ performance time by $3 \%$. A 260 cumulative effect of menthol and ice slurry or cold water was observed on performances during a $26120-\mathrm{km}$ cycling trial in hot environment $\left(30.7 \pm 0.8^{\circ} \mathrm{C}\right.$ and $\left.78 \pm 0.03 \% \mathrm{RH}\right)$ (Tran Trong et al. 2015). 262 Ultimately, menthol mouth rinsing and ingesting influence thermal perception and thermal comfort, 263 which in turn might contribute to enhance performance in hot climates (Stevens et al. 2017a; 264 Stevens et al. 2016).

\subsection{Cooling policy and implementation}

According to the literature, pre-cooling by ice or cold water has been successfully studied 268 during short duration exercise $(<60 \mathrm{~min})$ that is too brief to be a key factor of performance during 269 ultra-endurance trials (Siegel et al. 2012; Stevens et al. 2017b). Conversely, per-cooling by cold 270 water or ice slurry ingestion during exercise seems to be a very interesting intervention to improve 271 performances in a hot environment and possibly increase fluid intake, particularly for well-trained 
272 athletes (see chapter 7). Indeed, most high-performing runners show the biggest increase in internal 273 temperature, probably due to higher thermogenesis consecutive to higher workloads (Baillot et al. 274 2014; Hue et al. 2014). Faster trail runners (27 km; Baillot et al. 2014) and multi-stages trail runners 275 (127 km on 6 days; Hue et al. 2014) also present greater post-race dehydration, which could be 276 reduced by cold water due to its effect on voluntarily increasing water absorption during exercise. 277 The higher temperatures and greater dehydration observed in faster trail runners also seem to 278 indicate that performance in heat is associated with a better tolerance to hyperthermia in elite 279 athletes (McKeag and Moeller 2007).

\subsection{Heat acclimation}

Heat acclimation (HA) before a race is an efficient way to increase performance in a hot 284 physiological adaptations of HA lead to better cardiovascular function (output, stroke volume, heart 285 rate) and a decreased core temperature at rest and during exercise, in part due to an enhanced sweat 286 rate and expanded plasma volume (Armstrong and Maresh 1991). HA is also known to reduce 287 sodium loss by sweating (Kirby and Convertino 1986). However, HA does not fully restore long to 288 ultra-long endurance performance to the level reached by athletes in temperate conditions (Voltaire 289 et al. 2002).

If early arrival at the race location is not possible, $\mathrm{HA}$ in an environmental chamber is a 291 strategy that may help preserve ultramarathon performance. (Costa et al. 2014) examined the effects 292 of six 2-h sessions of running at $60 \%$ of $\mathrm{VO}_{2 \max }$ on a motorized treadmill in an environmental heat 293 chamber at $30^{\circ} \mathrm{C}$ or $35^{\circ} \mathrm{C}$. From the third session onward, mean heart rate was lower at $30^{\circ} \mathrm{C}$, 294 whereas mean heart rate and thermal comfort were lower at $35^{\circ} \mathrm{C}$. The authors concluded that two 295 bouts of running at $60 \%$ of $\mathrm{VO}_{2 \max }$ in a $30^{\circ} \mathrm{C}$ air temperature conditions were sufficient to induce 296 heat acclimation in ultra-runners, which may enhance their performance in such environments. 


\section{Conclusions}

300 The maintenance of triathlon or ultramarathon performance in a hot environment is a 301 considerable challenge which requires meticulous preparation and management during the race. To 302 limit the performance decrements induced by these harsh environmental conditions, several 303 countermeasures have been proposed, such as cold-water or ice slurry ingestion, external pre- and 304 per- cooling and/or menthol use. However, the limited duration of exercise performed in these 305 studies does not allow for direct application of the results to an ultra-endurance or ultra-triathlon 306 context. Thus, further studies are required to validate these approaches in long to triathlon and ultra307 endurance events.

308 Currently, one of the most relevant strategies to employ when performing in the heat is to 309 consume adequate fluids. Maintaining water availability along different race courses is thus crucial 310 due to the detrimental effects dehydration has on fluid balance and consequently heat loss via 311 sweating. Individual sweat rates are highly dependent on the athlete's morphology, the intensity of 312 exercise and the environment temperature and humidity. Sweat losses are accompanied by 313 electrolyte losses, particularly sodium, which may contribute to hyponatremia if not compensated. 314 To limit this risk, exogenous intake by enriched sodium beverages is the most effective strategy. In 315 addition to the traditional compounds found in most sport drinks (e.g. glucose, magnesium,), it 316 seems that ultramarathon beverages should contain about $0.7-1.2 \mathrm{~g} . \mathrm{L}^{-1}$ of salt when conducted in 317 the heat. However, sodium-enriched beverages are insufficient if athletes overdrink by fear of 318 dehydration during the race, placing management of water intake as a key determinant of 319 performance. 
321 performance in hot environments. Most of the acclimation benefits occur in the first 14 days of 322 exposure, but a short-term protocol of 5 days will induce significant early adaptations. 


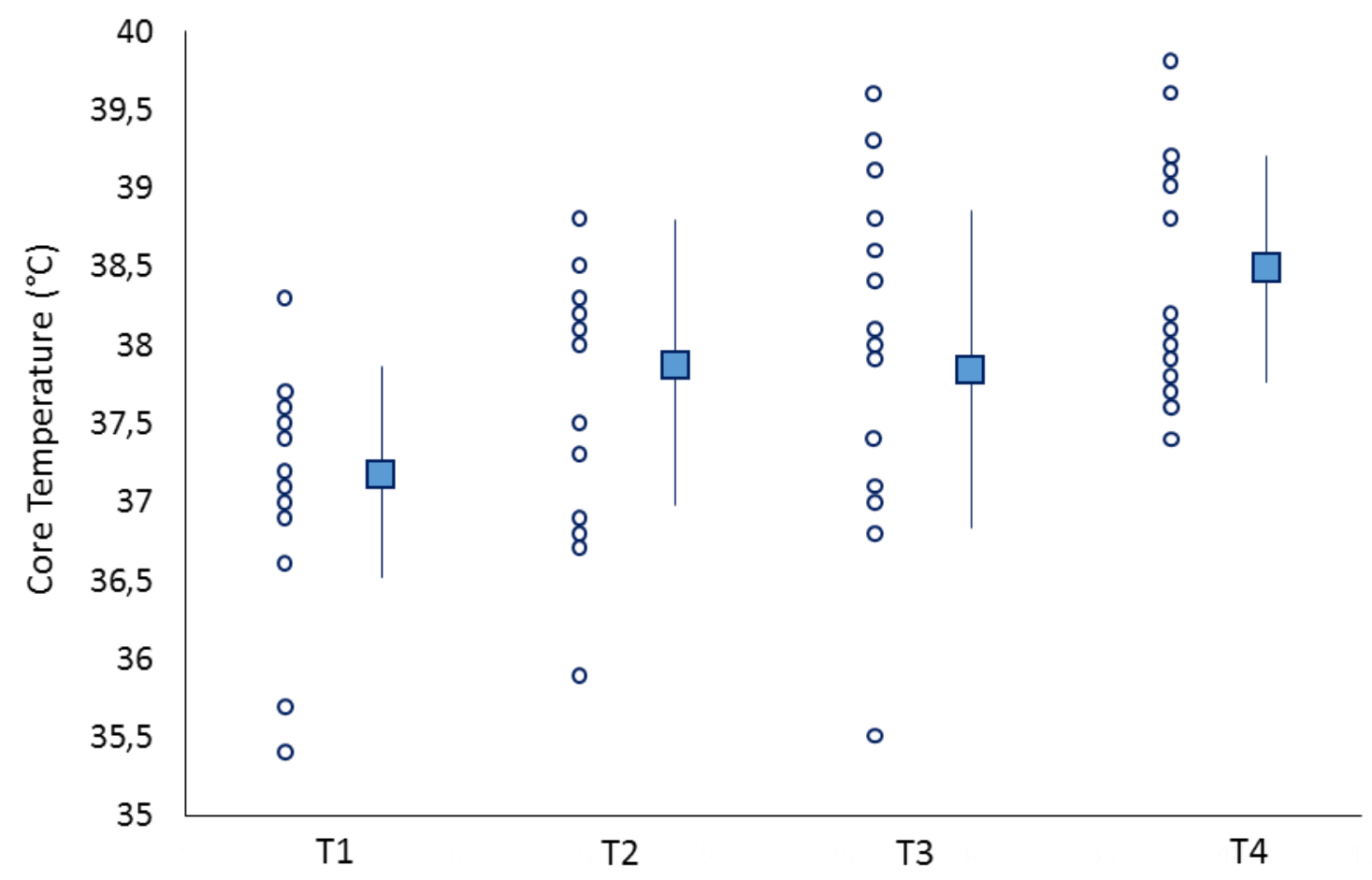

Figure 1. Individual and mean values $( \pm \mathrm{SD})$ of core temperature at each stage of the Guadeloupe halfIronman held in tropical climate. T1: just before the race; T2: after the swim phase; T3: after the cycle phase; T4: at the end of the run phase (Baillot and Hue 2015). Temperatures were obtained from telemetric intestinal temperature devices ingested at least 6 hours before the race. 


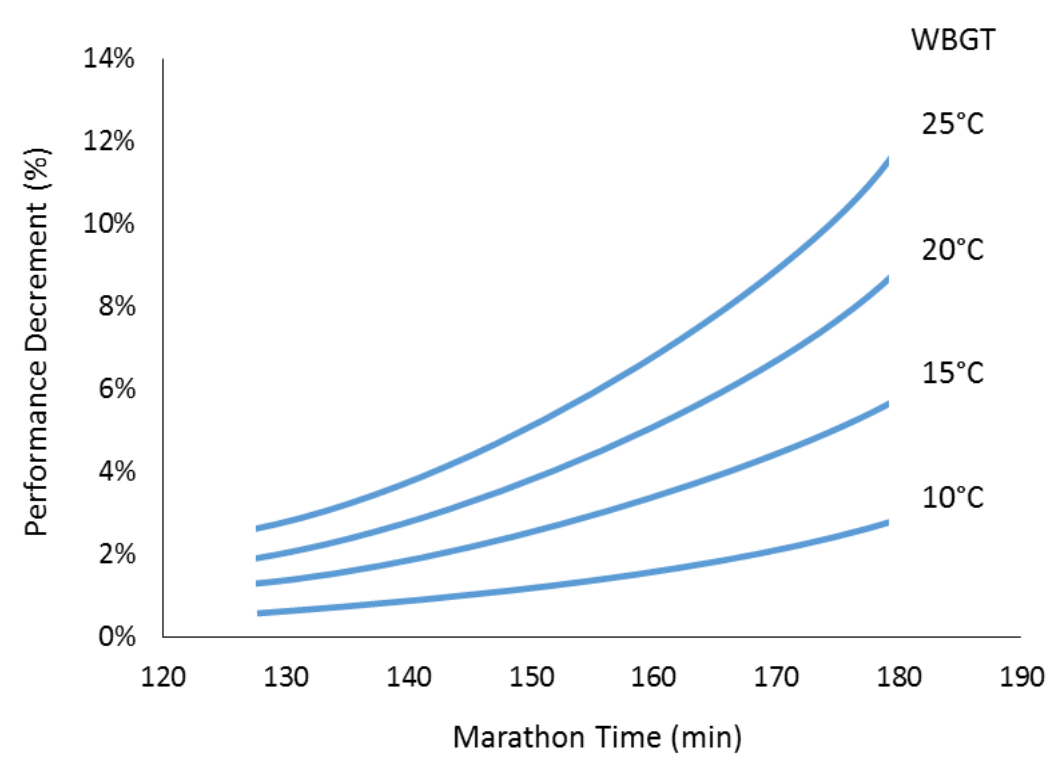

328 Figure 2. Nomogram representing the impact of WBGT on the relation between marathon finishing times 329 according to quartiles and relative performance decrement in comparison with WBGT at $5^{\circ} \mathrm{C}$ (Ely et al. 330 2007). 
A

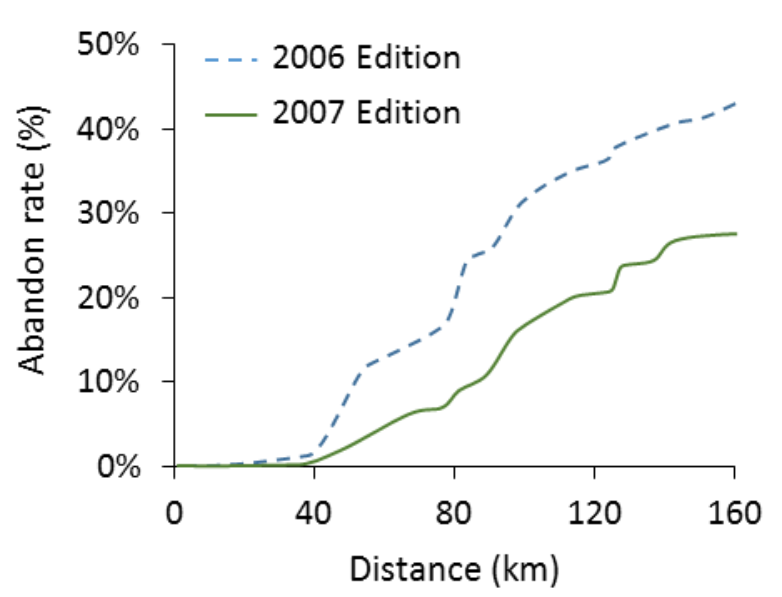

B

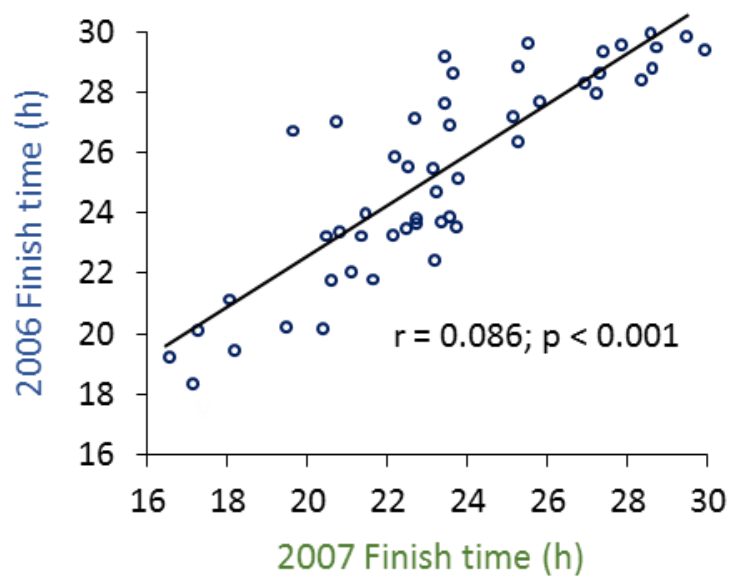

333 Figure 3. Proportion of runners abandoning the Western States Endurance Run (161 km; 6000m D+) race at 334 each checkpoint along the course (A), and relationship between finish times for the $2006\left(7-38^{\circ} \mathrm{C}\right)$ and 2007 $335 \quad\left(2-30^{\circ} \mathrm{C}\right)$ edition (B). (Parise and Hoffman 2011). 


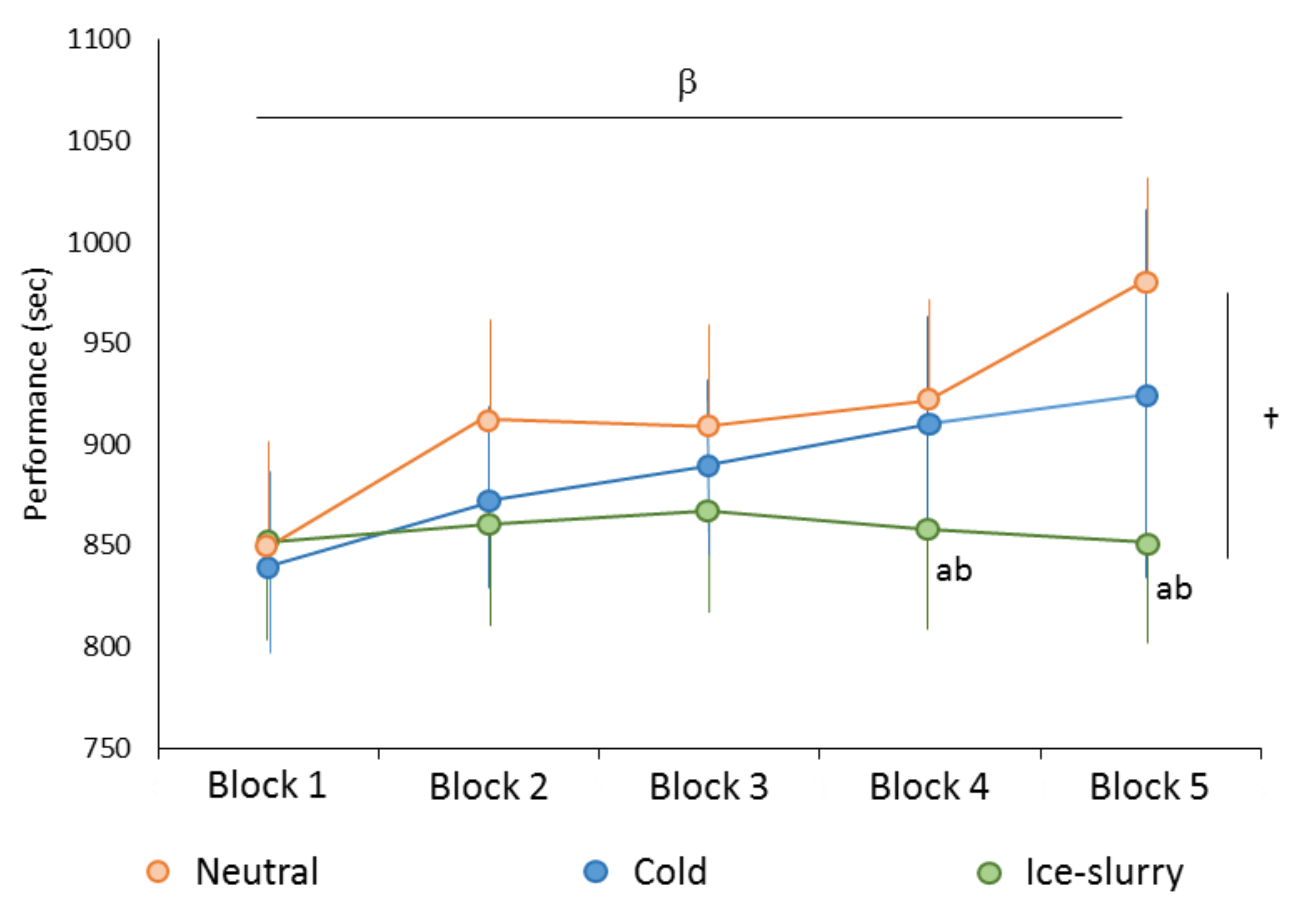

Figure 4. Trial times for 5 successive blocks ( $4 \mathrm{~km}$ cycling $+1.5 \mathrm{~km}$ running) with the ingestion of Neutral water (orange), Cold water (blue) and Ice-slurry (green).

a Significantly different from Neutral water Cycling and Running Performance Using IceSlurry/Menthol $(\mathrm{P}<0.05)$.

${ }^{\mathrm{b}}$ Significantly different from Cold $(\mathrm{P}<0.05)$. Mean values and SD are shown.

$\beta, \dagger$ denote that block performance was affected by Time Period $(\mathrm{P}<0.007)$ and the Time Period $\mathrm{x}$ Drink Temperature interaction $(\mathrm{P}<0.004)$, respectively (Tran Trong et al. 2015). 
Ansley L, Marvin G, Sharma A, Kendall MJ, Jones DA, Bridge MW (2008). The effects of head cooling on endurance and neuroendocrine responses to exercise in warm conditions. Physiol Res. 57:863-872

Armstrong LE, Maresh CM (1991). The induction and decay of heat acclimatisation in trained athletes. Sports Med. 12:302-312

Arngrimsson SA, Petitt DS, Stueck MG, Jorgensen DK, Cureton KJ (2004). Cooling vest worn during active warm-up improves 5-km run performance in the heat. J Appl Physiol (1985). 96:1867-1874

Baillot M, Hue O (2015). Hydration and thermoregulation during a half-ironman performed in tropical climate. J Sports Sci Med. 14:263-268

Baillot M, Le Bris S, Hue O (2014). Fluid replacement strategy during a 27-Km trail run in hot and humid conditions. Int J Sports Med. 35:147-152

Bergeron MF (2003). Heat cramps: fluid and electrolyte challenges during tennis in the heat. J Sci Med Sport. 6:19-27

Britt R (2011) North American Ironman DNF Rates: Finishers and DNF by Race. http://www.runtri.com/2010/09/north-american-ironman-dnf-rates.html.

Brotherhood JR (2008). Heat stress and strain in exercise and sport. J Sci Med Sport. 11:6-19

Brown JS, Connolly D (2015). Food and Fluid Intake During Extreme Heat: Experiences From The Badwater Ultramarathon. Wilderness \& Environmental Medicine. 26:e4

Burdon CA, Hoon MW, Johnson NA, Chapman PG, O'Connor HT (2013). The effect of ice slushy ingestion and mouthwash on thermoregulation and endurance performance in the heat. Int $\mathbf{J}$ Sport Nutr Exerc Metab. 23:458-469

Costa RJ, Crockford MJ, Moore JP, Walsh NP (2014). Heat acclimation responses of an ultraendurance running group preparing for hot desert-based competition. Eur J Sport Sci. 14 Suppl 1:S131-141

Del Coso J et al. (2016). Effects of oral salt supplementation on physical performance during a halfironman: A randomized controlled trial. Scand J Med Sci Sports. 26:156-164

Del Coso J et al. (2014). Relationship between physiological parameters and performance during a half-ironman triathlon in the heat. J Sports Sci. 32:1680-1687

Ely MR, Cheuvront SN, Roberts WO, Montain SJ (2007). Impact of weather on marathon-running performance. Med Sci Sports Exerc. 39:487-493

Gagnon D, Jay O, Kenny GP (2013). The evaporative requirement for heat balance determines whole-body sweat rate during exercise under conditions permitting full evaporation. J Physiol. 591:2925-2935

Galloway SD, Maughan RJ (1997). Effects of ambient temperature on the capacity to perform prolonged cycle exercise in man. Med Sci Sports Exerc. 29:1240-1249

Giambelluca T et al. (2014). Evapotranspiration of Hawai'i: final report to the US Army Corps of Engineers-Honolulu District and the Commission on Water Resource Management, State of Hawai'i, $178 \mathrm{p}$.

Glace BW, Murphy CA, McHugh MP (2002). Food intake and electrolyte status of ultramarathoners competing in extreme heat. J Am Coll Nutr. 21:553-559

Harris KM, Henry JT, Rohman E, Haas TS, Maron BJ (2010). Sudden death during the triathlon. JAMA. 303:1255-1257

Hasegawa H, Takatori T, Komura T, Yamasaki M (2005). Wearing a cooling jacket during exercise reduces thermal strain and improves endurance exercise performance in a warm environment. J Strength Cond Res. 19:122-128 
Hew-Butler $\mathrm{T}$ et al. (2008). Statement of the Second International Exercise-Associated Hyponatremia Consensus Development Conference, New Zealand, 2007. Clin J Sport Med : official journal of the Canadian Academy of Sport Medicine. 18:111-121

Hoffman MD, Stuempfle KJ (2014). Hydration strategies, weight change and performance in a 161 km ultramarathon. Res Sports Med. 22:213-225

Hoffman MD, Stuempfle KJ, Rogers IR, Weschler LB, Hew-Butler T (2012). Hyponatremia in the 2009 161-km Western States Endurance Run. Int J Sports Physiol Perform. 7:6-10

Hue O, Henri S, Baillot M, Sinnapah S, Uzel AP (2014). Thermoregulation, hydration and performance over 6 days of trail running in the tropics. Int J Sports Med. 35:906-911

Hue O, Voltaire B, Hertogh C, Blonc S (2006). Heart rate, thermoregulatory and humoral responses during a 9-day cycle race in a hot and humid climate. Int J Sports Med. 27:690-696
Ironman
(2018)
Rules
and

http://m.eu.ironman.com/triathlon/events/emea/ironman/tallinn/athletes/rules-andregulations.aspx.

Kenefick RW (2018). Drinking Strategies: Planned Drinking Versus Drinking to Thirst. Sports Med. 48:31-37

Kenefick RW, Cheuvront SN, Sawka MN (2007). Thermoregulatory function during the marathon. Sports Med. 37:312-315

Kerr CG, Trappe TA, Starling RD, Trappe SW (1998). Hyperthermia during Olympic triathlon: influence of body heat storage during the swimming stage. Med Sci Sports Exerc. 30:99-104

Kirby CR, Convertino VA (1986). Plasma aldosterone and sweat sodium concentrations after exercise and heat acclimation. J Appl Physiol (1985). 61:967-970

Knechtle B, Knechtle P, Rosemann T (2011). Low prevalence of exercise-associated hyponatremia in male $100 \mathrm{~km}$ ultra-marathon runners in Switzerland. Eur J Appl Physiol. 111:1007-1016

Latzka WA, Sawka MN (2000). Hyperhydration and glycerol: thermoregulatory effects during exercise in hot climates. Can J Appl Physiol. 25:536-545

Latzka WA, Sawka MN, Montain SJ, Skrinar GS, Fielding RA, Matott RP, Pandolf KB (1997). Hyperhydration: thermoregulatory effects during compensable exercise-heat stress. J Appl Physiol (1985). 83:860-866

Laursen PB et al. (2006). Core temperature and hydration status during an Ironman triathlon. Br J Sports Med. 40:320-325; discussion 325

Laursen PB, Watson G, Abbiss CR, Wall BA, Nosaka K (2009). Hyperthermic fatigue precedes a rapid reduction in serum sodium in an ironman triathlete: a case report. Int J Sports Physiol Perform. 4:533-537

Lebus DK, Casazza GA, Hoffman MD, Van Loan MD (2010). Can changes in body mass and total body water accurately predict hyponatremia after a $161-\mathrm{km}$ running race? Clin J Sport Med: official journal of the Canadian Academy of Sport Medicine. 20:193-199

Luomala MJ, Oksa J, Salmi JA, Linnamo V, Holmér I, Smolander J, Dugue B (2012). Adding a cooling vest during cycling improves performance in warm and humid conditions. Journal of Thermal Biology. 37:47-55

Marino FE, Mbambo Z, Kortekaas E, Wilson G, Lambert MI, Noakes TD, Dennis SC (2000). Advantages of smaller body mass during distance running in warm, humid environments. Pflugers Arch. : European journal of physiology. 441:359-367

Maughan RJ (1991). Fluid and electrolyte loss and replacement in exercise. J Sports Sci. 9 Spec No:117-142

Maughan RJ (2010). Distance running in hot environments: a thermal challenge to the elite runner. Scand J Med Sci Sports. 20 Suppl 3:95-102

Maughan RJ, Otani H, Watson P (2012). Influence of relative humidity on prolonged exercise capacity in a warm environment. Eur J Appl Physiol. 112:2313-2321

McKeag D, Moeller JL (2007). ACSM's primary care sports medicine. Wolters Kluwer/Lippincott Williams \& Wilkins, 
Nielsen B (1994). Heat stress and acclimation. Ergonomics. 37:49-58

Nielsen B (1996). Olympics in Atlanta: a fight against physics. Med Sci Sports Exerc. 28:665-668 Noakes TD (2007). Drinking guidelines for exercise: what evidence is there that athletes should drink "as much as tolerable", "to replace the weight lost during exercise" or "ad libitum"? J Sports Sci. 25:781-796

Noakes TD, Goodwin N, Rayner BL, Branken T, Taylor RK (2005). Water intoxication: a possible complication during endurance exercise, 1985. Wilderness Environ Med. 16:221-227

Nybo L (2010). Cycling in the heat: performance perspectives and cerebral challenges. Scand J Med Sci Sports. 20 Suppl 3:71-79

Parise CA, Hoffman MD (2011). Influence of temperature and performance level on pacing a 161 km trail ultramarathon. Int J Sports Physiol Perform. 6:243-251

Riera F, Trong T, Rinaldi K, Hue O (2016). Precooling does not enhance the effect on performance of midcooling with ice-slush/menthol. Int J Sports Med. 37:1025-1031

Ross ML, Jeacocke NA, Laursen PB, Martin DT, Abbiss CR, Burke LM (2012). Effects of lowering body temperature via hyperhydration, with and without glycerol ingestion and practical precooling on cycling time trial performance in hot and humid conditions. J Int Soc Sports Nutr. 9:55

Saat M, Sirisinghe RG, Singh R, Tochihara Y (2005a). Effects of short-term exercise in the heat on thermoregulation, blood parameters, sweat secretion and sweat composition of tropicdwelling subjects. J Physiol Anthropol Appl Human Sci. 24:541-549

Saat M, Tochihara Y, Hashiguchi N, Sirisinghe RG, Fujita M, Chou CM (2005b). Effects of exercise in the heat on thermoregulation of Japanese and Malaysian males. J Physiol Anthropol Appl Human Sci. 24:267-275

Sawka MN, Francesconi RP, Young AJ, Pandolf KB (1984). Influence of hydration level and body fluids on exercise performance in the heat. JAMA. 252:1165-1169

Sawka MN, Montain SJ, Latzka WA (2001). Hydration effects on thermoregulation and performance in the heat. Comp Biochem Physiol A Mol Integr Physiol. 128:679-690

Sawka MN, Noakes TD (2007). Does dehydration impair exercise performance? Med Sci Sports Exerc. 39:1209

Scheadler CM (2009) Glycerol hyperhydration and endurance running performance in the heat. The Ohio State University.

Shirreffs SM, Sawka MN (2011). Fluid and electrolyte needs for training, competition, and recovery. J Sports Sci. 29 Suppl 1:S39-46

Siegel R, Mate J, Brearley MB, Watson G, Nosaka K, Laursen PB (2010). Ice slurry ingestion increases core temperature capacity and running time in the heat. Med Sci Sports Exerc. 42:717-725

Siegel R, Mate J, Watson G, Nosaka K, Laursen PB (2012). Pre-cooling with ice slurry ingestion leads to similar run times to exhaustion in the heat as cold water immersion. J Sports Sci. 30:155-165

Speedy DB et al. (2001). Fluid balance during and after an ironman triathlon. Clin J Sport Med. $11: 44-50$

Speedy DB et al. (1999). Hyponatremia in ultradistance triathletes. Med Sci Sports Exerc. 31:809815

Stevens CJ, Bennett KJ, Sculley DV, Callister R, Taylor L, Dascombe BJ (2017a). A Comparison of Mixed-Method Cooling Interventions on Preloaded Running Performance in the Heat. J Strength Cond Res. 31:620-629

Stevens CJ, Best R (2017). Menthol: A Fresh Ergogenic Aid for Athletic Performance. Sports Med. 47:1035-1042

Stevens CJ, Kittel A, Sculley DV, Callister R, Taylor L, Dascombe BJ (2017b). Running performance in the heat is improved by similar magnitude with pre-exercise cold-water immersion and mid-exercise facial water spray. J Sports Sci. 35:798-805 
Stevens CJ, Thoseby B, Sculley DV, Callister R, Taylor L, Dascombe BJ (2016). Running performance and thermal sensation in the heat are improved with menthol mouth rinse but not ice slurry ingestion. Scand J Med Sci Sports. 26:1209-1216

Stiefel M, Knechtle B, Rüst CA, Rosemann T (2013). Analysis of performances at the'Ironman Hawaii triathlon'and its qualifier events with respect to nationality. Journal of Science and Cycling. 2:27

Stuempfle KJ, Hoffman MD, Weschler LB, Rogers IR, Hew-Butler T (2011). Race diet of finishers and non-finishers in a 100 mile $(161 \mathrm{~km})$ mountain footrace. J Am Coll Nutr. 30:529-535

Tam N, Hew-Butler T, Papadopoulou E, Nolte H, Noakes TD (2009). Fluid intake and changes in blood biochemistry, running speed and body mass during an $80 \mathrm{~km}$ mountain trail race. Med Sport. 13:108-115

Taylor NA (2006). Challenges to temperature regulation when working in hot environments. Industrial health. 44:331-344

Teunissen LP, Grabowski A, Kram R (2007). Effects of independently altering body weight and body mass on the metabolic cost of running. J Exp Biol. 210:4418-4427

Tran Trong T, Riera F, Rinaldi K, Briki W, Hue O (2015). Ingestion of a cold temperature/menthol beverage increases outdoor exercise performance in a hot, humid environment. PloS one. 10:e0123815

Trappe T, Pease D, Trappe S, Troup J, Burke E (1996). Physiological responses to swimming while wearing a wet suit. Int J Sports Med. 17:111-114

Tyler CJ, Sunderland C (2011). Neck cooling and running performance in the heat: single versus repeated application. Med Sci Sports Exerc. 43:2388-2395

Voltaire B, Berthouze-Aranda S, Hue O (2003). Influence of a hot/wet environment on exercise performance in natives to tropical climate. J Sports Med Phys Fitness. 43:306-311

Voltaire B et al. (2002). Effect of fourteen days of acclimatization on athletic performance in tropical climate. Can J Appl Physiol. 27:551-562

Von Duvillard SP, Braun WA, Markofski M, Beneke R, Leithauser R (2004). Fluids and hydration in prolonged endurance performance. Nutrition. 20:651-656

Vrijens DM, Rehrer NJ (1999). Sodium-free fluid ingestion decreases plasma sodium during exercise in the heat. J Appl Physiol (1985). 86:1847-1851

Wu SS, Peiffer JJ, Brisswalter J, Nosaka K, Lau WY, Abbiss CR (2015). Pacing strategies during the swim, cycle and run disciplines of sprint, Olympic and half-Ironman triathlons. Eur J Appl Physiol. 115:1147-1154

Yeo ZW, Fan PW, Nio AQ, Byrne C, Lee JK (2012). Ice slurry on outdoor running performance in heat. Int J Sports Med. 33:859-866

Zaryski C, Smith DJ (2005). Training principles and issues for ultra-endurance athletes. Curr Sports Med Rep. 4:165-170 